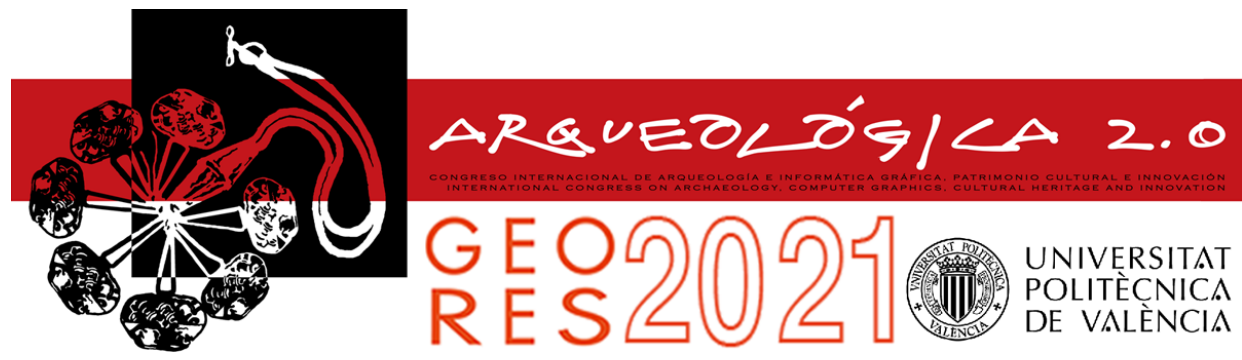

Proceedings of the joint international event $9^{\text {th }}$ ARQUEOLÓGICA

$2.0 \& 3^{\text {rd }}$ GEORES

Valencia (Spain).

26-28 April 2021

\title{
GEOMATICS ADVANCED IMAGE-BASED TECHNIQUES FLANKING ARCHAEOLOGICAL RESEARCH. A NOTEWORTHY AREA IN THE NORTHERN NECROPOLIS OF HIERAPOLIS OF FRIGIA (TK)
}

\author{
Lorenzo Teppati Losè ${ }^{a,},{ }^{,}$Antonia Spanòa, Anna Anguissola ${ }^{b}$ \\ ${ }^{a}$ Laboratory of Geomatics for Cultural Heritage $(\mathrm{G} 4 \mathrm{CH})$, Department of Architecture and Design (DAD), Politecnico di Torino, Viale \\ Mattioli 39, 10125 Torino, Italy. Iorenzo.teppati@polito.it; antonia.spano@polito.it \\ b Department of Civilizations and Forms of Knowledge, University of Pisa, Via dei Mille 19, 56126 Pisa, Italy. anna.anguissola@unipi.it
}

\begin{abstract}
:
The paper relates the studies aimed at experimenting with aerial and terrestrial methods of rapid mapping survey applied in an archaeological context, and at evaluating the effectiveness of their results in relation to the purposes of archaeological researches. Different UAV (Unmanned aerial vehicle) and $360^{\circ}$ camera data acquisition and processing strategies are reported and discussed. The integration and fusion approaches have been investigated taking advantages of coregistration approaches. Archaeologists from the University of Pisa have investigated areas of the northern necropolis at Hierapolis since 2017, exploring the arrangement and use of Roman sarcophagi in their architectural context. Thanks to a full review of the archaeological and epigraphic evidence from Tomb 159c, and thanks to the high detailed 3D models and high-resolution orthophotos derived with geomatics techniques, it has been possible to reconstruct patterns and changes in ownership, use, and movement in a significant section of the necropolis across three centuries.
\end{abstract}

Keywords: archaeological heritage, UAVs, SfM, spherical photogrammetry

\section{Introduction}

The research objectives were directed towards the study of the applicability of the rapid mapping survey approaches, within a complex archaeological context such as that of the city of Hierapolis of Phrygia. This methodological aspect was combined with the need for continuous documentation of the excavations and archaeological studies on the ancient city.

In relation to its size, the site of Hierapolis boasts one of the largest concentrations of graves known in the Roman world. Some 600 monumental tombs with a remarkable variety of architectural types have been identified north, east, and south of the ancient city, ranging from the $2^{\text {nd }}$ century BCE to Late Antiquity. Scattered between the monuments, marble and stone sarcophagi are almost everywhere, from the city limits to the top of the hills.

Researchers from the University of Pisa have been investigating the burial grounds of Hierapolis since 2008 (Anguissola, Bochicchio, Calabrò, \& Costa, 2012; 2013; 2014 ; 2016), aiming at a contextual study of both their funerary monuments and sarcophagi. In a broader perspective, this program aims at initiating a more articulate discussion on Roman funerary practices in light of individual, exceptionally informative case studies. During the 2017-2019 campaigns, attention focused on an area in the Northern necropolis where monuments and sarcophagi seem to have clustered for centuries, causing a series of changes both in the layout of the burial ground and in the road system across it.

In order to fully understand the layout and the history of this area, advanced survey techniques were required to assist in the archaeological, architectural, epigraphical, and art-historical investigations. Firstly, it seemed necessary to survey and map a larger area than direct, unassisted methods would allow. Secondly, the scope of the research called for highly detailed images and comprehensive data-sets, able to account for the features of the terrain (altitude, slopes, passages, staircases, terraces, aligned buildings which may indicate earlier road systems)

\section{Data acquisition. Consolidated and experimental approaches}

As presented in the introduction to this paper, survey campaigns in the Northern Necropolis of Hierapolis are part of a wider project of documentation developed thanks to different field campaigns completed during the last years in the Turkish archaeological site. A first approach to the documentation of this area was completed in 2015 by mean of a UAV fixed-wing platform (Chiabrando, D'Andria, Sammartano, \& Spanò, 2018). Only a small

`Corresponding Author: Lorenzo Teppati Losè, Iorenzo.teppati@polito.it 
portion of the Northern Necropolis was acquired in this first UAVs flight (the southern part). The flights performed were aimed at documenting a large area of the archaeological site with the accuracies and level of detail proper for an overview investigation (1:200/1:500 nominal scale).

The second step in the process of documentation was accomplished in the 2017 campaign. In this campaign, all the area of the Northern Necropolis was included in a dedicated UAVs medium-altitude acquisition (40-50 meters flight altitude), with a multi-rotor platform, to reach a higher level of details in comparison with the 2015 flight and with higher overall accuracy. Finally, part of the 2018 field campaign was devoted to the documentation of a smaller section of the necropolis, the area included between tomb 163 and 159d. It is in this area (highlighted in Figure 1, together with the area acquired in 2017) that archaeologists from the University of Pisa focused their investigation.

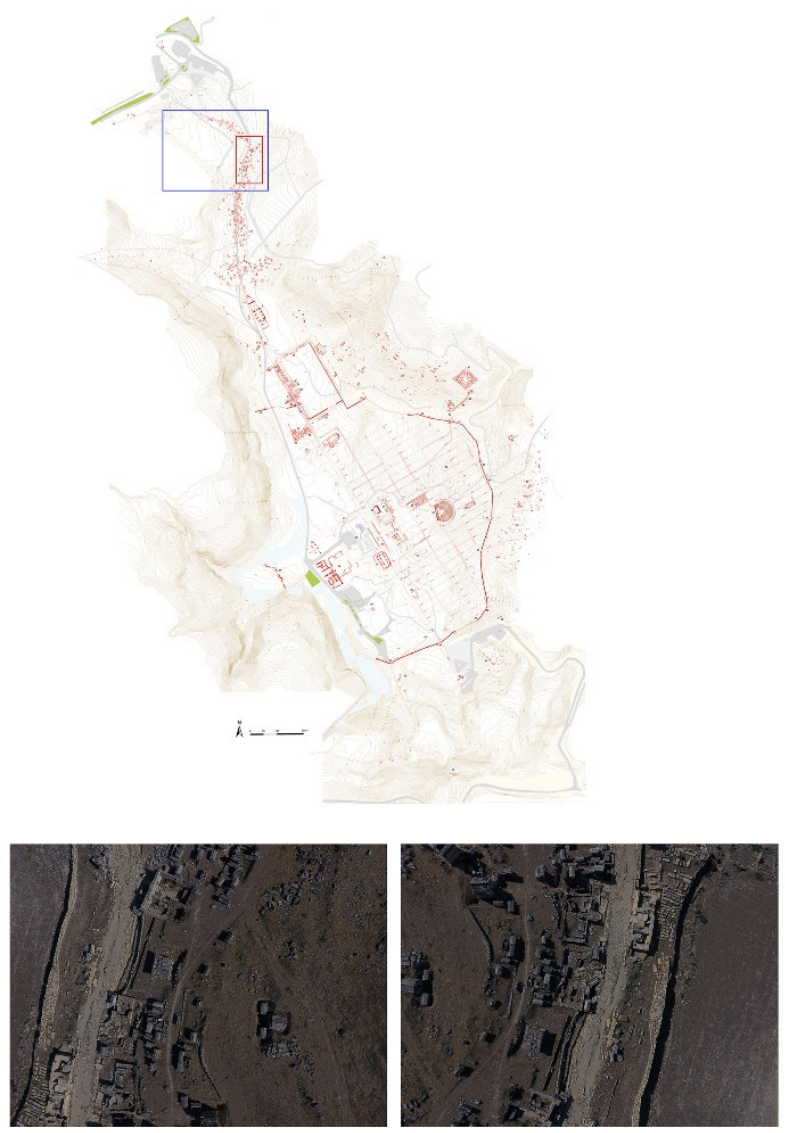

Figure 1: Northern Necropolis of Hierapolis, the area acquired in 2017 is highlighted in blue while the area acquired in 2018 is highlighted in red (from D'Andria, Scardozzi, \& Spanò, 2008). Below an example of two images acquired in 2017.

In the 2018 field campaign, different geomatic techniques were deployed to achieve a complete and high detail multi-scale and multi-sensor documentation of this area. Both consolidated and more experimental approaches were thus adopted in the field, with the aim of testing also rapid mapping approaches by mean of COTS (Commercial Off The Shelf) sensors in parallel with more established techniques. The area was firstly imaged with manually operated low altitude UAV flights; a series of TLS (Terrestrial Laser Scanner) acquisitions were completed and finally, acquisitions with a $360^{\circ}$ camera were performed as well (some acquisitions with a handheld laser scanner based on SLAM - Simultaneous Localization And Mapping technology were achieved, but they will not be referred to in the present paper).

In particular, the use of $360^{\circ}$ cameras for the documentation of cultural heritage has quite a long history in the geomatics community (D'Annibale, Piermattei, \& Fangi, 2011; Fangi \& Nardinocchi, 2013), however, thanks to the development of SfM (Structure from Motion) algorithms and the availability of new low-cost $360^{\circ}$ systems it has gained new interest in the last years (Fangi, Pierdicca, Sturari, \& Malinverni, 2018; Gottardi \& Guerra, 2018; Ramos \& Prieto, 2016), opening new research addresses.

It should be noted that in all the campaigns completed in the site of Hierapolis of Phrygia the metric control and the georeferencing of all the acquisitions in the same coordinate system was guaranteed thanks to the measurement of different sets of control points in the field by mean of traditional topographic techniques (e.g. total station and GNSS). This operation was made possible by the network of topographic vertices that had been created, measured, and integrated in the archaeological site during the past decades (D'Andria, Scardozzi, \& Spanò, 2008), and that has been useful also for topographical measurements performed by other teams (Scardozzi, 2015).

For the purposes of the research presented in this manuscript, the focus will be on medium-altitude UAV photogrammetric surveys and $360^{\circ}$ camera acquisitions, and on possible approaches to integrating them. Moreover, not all the employed and tested techniques will be discussed.

\subsection{The northern necropolis rapid mapping general documentation (2017 acquisitions)}

Part of the 2017 field campaigns was thus dedicated to integrating and updating the data collected on the Northern Necropolis in 2015. The main aim of these acquisitions was to achieve complete coverage of all the necropolis with UAVs flights at a medium altitude to generate metric products of this area at a large scale (1:100/1:200): namely 3D model, DSM (Digital Surface Model) and orthophoto. The experience gained in previous researches dedicated to the optimization of the flight planning phases for UAVs acquisition in archaeological and architectural contexts (Chiabrando, Lingua, Maschio, \& Teppati Losè, 2017; Chiabrando \& Teppati Losè, 2017) as well as other researches available in the literature (e.g. Hernández-Lopez, Felipe-Garcia, Gonzalez-Aguilera, \& Arias-Perez, 2013; Nex \& Remondino, 2014; Remondino, Barazzetti, Nex, Scaioni, \& Sarazzi, 2012) allowed to complete all the acquisition phases for the area of interest $\left(\approx 0.2 \mathrm{~km}^{2}\right)$ in few hours, including also the phase of control points positioning and measurement.

In 2017 a total number of five flights were performed on the area of the Northern Necropolis:

- Three nadiral flights were completed with an orientation of the flight lines that followed the main urban organization of buildings and its road network. These flights aimed also to include a 
wider part of the area around the necropolis' monuments to define the terrain and the environment in which the tombs insist.

- Two oblique acquisitions were integrated into the area where the concentration of monuments is higher, in order to achieve a higher detail in terms of completeness of the geometrical reconstruction. Flight lines of these flights were designed to be interconnected with the other three nadiral flights.

An overview of the flight plans completed in this area in 2017 is shown in Figure 2, while the main parameters of the five flights are reported in Table 1.
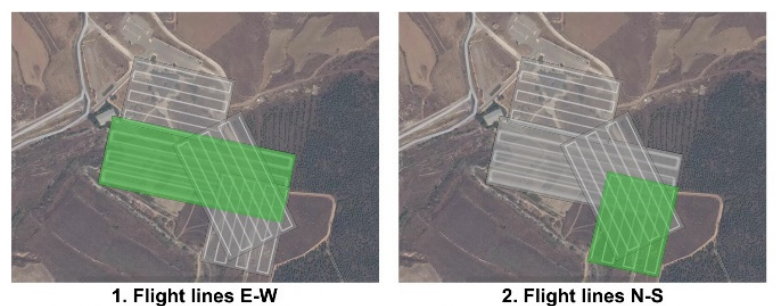

Nadrial configuration of camera

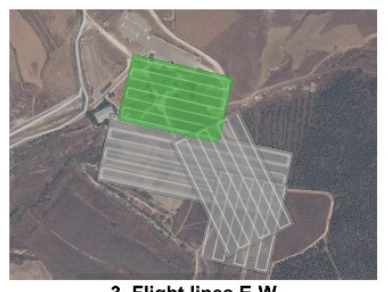

3. Flight lines E-W Nadrial configuration of camera
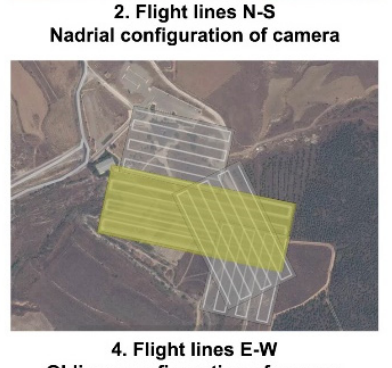

Oblique configuration of camera

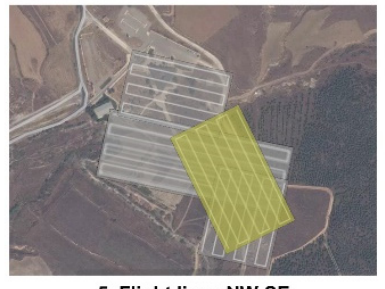

5. Flight lines NW-SE

Oblique configuration of camera

Figure 2: Northern Necropolis of Hierapolis. 2017 flight planning and camera orientation.

Table 1: Northern Necropolis of Hierapolis. 2017 flights main characteristics.

\begin{tabular}{c|c|c|c|c}
$I D$ & $\begin{array}{c}N^{\circ} \\
\text { Images }\end{array}$ & $\begin{array}{c}\text { Camera } \\
\text { configuration }\end{array}$ & $\begin{array}{c}\text { Flight time } \\
(\text { min })\end{array}$ & $\begin{array}{c}\text { Flight } \\
\text { altitude }(\mathrm{m})\end{array}$ \\
\hline 1 & 215 & Nadir & 10 & $40-50$ \\
2 & 115 & Nadir & 6 & $40-50$ \\
3 & 127 & Nadir & 6 & $40-50$ \\
4 & 159 & Oblique & 8 & $40-50$ \\
5 & 126 & Oblique & 6 & $40-50$
\end{tabular}

All the flights completed in 2017 in this area were performed with a DJI Phantom 4. This quadcopter is equipped with a $4 \mathrm{~K}$ camera (1/2.3" CMOS sensor, 12.4 MP), $20 \mathrm{~mm}$ ( $35 \mathrm{~mm}$ equivalent) with a focus on infinity. It weighs $1.38 \mathrm{~kg}$ and has a maximum flight time of 28 minutes.

\subsection{Focusing on the noteworthy area of $159 \mathrm{~b}$ tomb (2018 acquisitions)}

As previously reported, during the 2018 campaign particular attention was set on the documentation of a specific portion of the Northern Necropolis. The field activities were conducted in accordance with and in cooperation with the Italian archaeologists that were working in that area on the same days. A complete documentation project was thus designed and executed involving the deployment in the field of different instruments and techniques. After the setup and measurement of a set of control points, homogenously distributed in the area and measured by mean of a total station with the final accuracy achieved in the order of few millimetres, several acquisitions were performed.

\subsubsection{UAVs acquisitions}

Firstly, the total number of seven manual UAVs flights were performed in this area. The choice of performing manual flights instead of the automatic pre-programmed was dictated by different reasons: the increased presence of tourists at the time of the flight operations, the morphological conformation of the area that develops on different levels, the presence of unauthorized UAVs piloted from the visitors of the site and finally the low details of the satellite images database for the area of interest that did not allow to precisely plan a flight for the high detail desired.

In this case, the choice of performing manual flights was also supported by the main characteristics of the two platforms available on the field (DJI Mavic Pro and DJI Spark) and by the conformation of the area that presents a high density of archaeological pieces of evidence scattered on different levels.

However, despite being fully manually performed, the flights were completed following the same criteria adopted for the pre-programmed automatic flight plans: a grid of waypoints, corresponding with the image acquisition positions was executed (still images were acquired for each waypoint); different orientation of the camera angles were used, in relation with the conformation of the area and the architectural arrangement of the necropolis' structures. An average overlap $(75-85 \%)$ has been maintained both for the frontal and lateral side between stripes. The Mavic Pro is equipped with a $4 \mathrm{~K}$ camera mounted on a 3-axis mechanical gimbal. The camera acquires video with $4 \mathrm{~K}$ resolution and images at $12.7 \mathrm{MP}$ (26 mm focal length). On the other side, the Spark is a mini drone that weights only $300 \mathrm{~g}$ and is equipped with a 12 MP camera (CMOS sensor of 1/2.3"; $25 \mathrm{~mm}$ focal length). The camera acquires images in $4 \mathrm{~K}(4: 3)$ and videos in full HD (16:9). The mechanical gimbal is stabilized only on 2-axis and has a controllable range of pitch from $0^{\circ}$ to $-85^{\circ}$.

Considering that the sensors mounted on the two platforms have similar characteristics it was decided to test combined use of the two UAVs. This choice allowed also to optimize the overall flight time and batteries performances. A total number of four flights was completed using the Mavic Pro while the Spark was deployed for the other three flights. Moreover, to obtain the same GSD, it was planned to use the two systems at slightly different altitudes in order to compensate for the different resolutions: for the flights achieved with the 
Spark a lower altitude was used. The main characteristics of the flights are reported in Tables 2 and 3.

Table 2: Northern Necropolis of Hierapolis. 2018 flights main characteristics. Mavic Pro.

\begin{tabular}{|c|c|c|c|c|}
\hline$I D$ & $\begin{array}{c}N^{\circ} \\
\text { Images }\end{array}$ & $\begin{array}{c}\text { Camera } \\
\text { configuration }\end{array}$ & $\begin{array}{l}\text { Flight time } \\
\text { (min) }\end{array}$ & $\begin{array}{c}\text { Flight } \\
\text { altitude }(m)\end{array}$ \\
\hline 1 & 127 & $\begin{array}{l}\text { Nadiral. Flight } \\
\text { lines } \mathrm{N}-\mathrm{S}\end{array}$ & 11 & $\approx 25$ \\
\hline 2 & 91 & $\begin{array}{l}\text { Nadiral. Flight } \\
\text { lines N-S }\end{array}$ & 7 & $\approx 25$ \\
\hline 3 & 130 & $\begin{array}{l}\text { Oblique. Flight } \\
\text { lines N-S. } \\
\text { Camera } \\
\text { direction: } \mathrm{E}\end{array}$ & 13 & $\approx 25$ \\
\hline 4 & 195 & $\begin{array}{l}\text { Oblique. Flight } \\
\text { lines N-S. } \\
\text { Camera } \\
\text { direction: W }\end{array}$ & 15 & $\approx 25$ \\
\hline
\end{tabular}

Table 3: Northern Necropolis of Hierapolis. 2018 flights main characteristics. Mavic Pro. Spark.

\begin{tabular}{c|c|c|c|c}
$I D$ & $\begin{array}{c}N^{\circ} \\
\text { Images }\end{array}$ & $\begin{array}{c}\text { Camera } \\
\text { configuration }\end{array}$ & $\begin{array}{c}\text { Flight time } \\
(\mathrm{min})\end{array}$ & $\begin{array}{c}\text { Flight } \\
\text { altitude }(\mathrm{m})\end{array}$ \\
\hline 5 & 86 & $\begin{array}{c}\text { Oblique. } \\
\text { Flight lines } \\
\text { W-E. Camera } \\
\text { direction: E } \\
\text { Oblique. } \\
\text { Flight lines } \\
\text { W-E. Camera } \\
\text { direction: W } \\
\text { Oblique. } \\
\text { Flight lines N- } \\
\text { S. Camera } \\
\text { direction: N } \\
\text { and S }\end{array}$ & 122 & $\approx 15$ \\
& 10 & $\approx 15$ \\
& &
\end{tabular}

\subsubsection{Acquisition with $360^{\circ}$ cameras}

Spherical cameras are designed to acquire all the environment around them so they may seem easy to use during the field phases, however, this impression can be tricky. As for the acquisitions with normal frame cameras different factors need to be considered and the acquisitions need to be completed respecting some basic principles. In a previous research work (Teppati Losè, 2019) the possibilities connected with the use of these systems for the development of terrestrial rapid mapping approaches in the field of built heritage documentation have been exploited and the acquisitions performed on the Northern Necropolis are part of this work as well. During the research performed in the previously cited work three different acquisition strategies were proposed and tested:

- $\quad$ Still images acquisition. This acquisition strategy requires the use of a tripod and the possibility of remotely control the camera. It is more effective in terms of quality of the acquired images but less efficient in terms of acquisition time due to the time needed to set up each single camera position.
- Time Lapse acquisition. This strategy takes advantage of the possibility of acquiring images at preselected intervals. Unlike the first strategy, it is possible to move the camera around the scene during the acquisition, however, movements should be quite slow and soft to preserve an acceptable quality of the acquired images.

- Video acquisition. This is the most efficient strategy in terms of acquisition time optimization thanks to two factors: the acquisition of a high number of frames, that can be downsampled and selected in post-processing, and the stabilization algorithms embedded in this kind of system for the video recording.

Considering all these issues, it is clear that also for $360^{\circ}$ cameras, the acquisition phase must be carefully designed and executed during the field activities especially when the last two acquisition modalities (timelapse and video) are adopted, and the operator is moving around the scene. It is thus important to previously design the acquisition path to follow in the field to maintain a constant sensor-object distance and a similar distance between camera positions. Different tests conducted showed that performing circular closed acquisition, with start and end point located in the same position, represents a good strategy to add constraints and improve the orientation phase. An example of circular acquisition performed in video mode is shown in Figure 3.

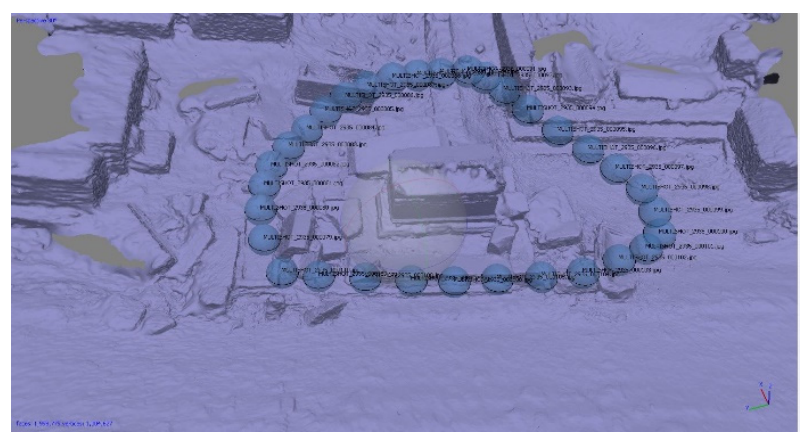

Figure 3: The 159b tomb area. Example of "circular" acquisition performed in video mode with a $360^{\circ}$ camera.

In the framework of 2018 activities, both time-lapse and video strategy were tested in the Northern Necropolis. The $360^{\circ}$ camera used was a GoPro Fusion: a small lightweight camera $(220 \mathrm{gr})$ that is equipped with two $1 / 2.3$ " CMOS sensor and can record video in $5.2 \mathrm{~K}$ and images with a max resolution of $18 \mathrm{MP}$. For both the acquisitions performed in this area a multipurpose tripod was used in order to let the operator freely move in the environment.

For the time lapse strategy, the shooting interval was set at 1 second and the path followed is reported in Figure $4 a$. The overall acquisition time was five minutes, during which 317 images were recorded and an area of $\approx 8.000$ $\mathrm{m}^{2}$ was covered. The mean acquisition distance from the camera to archaeological structures was between 3 and 5 meters. 

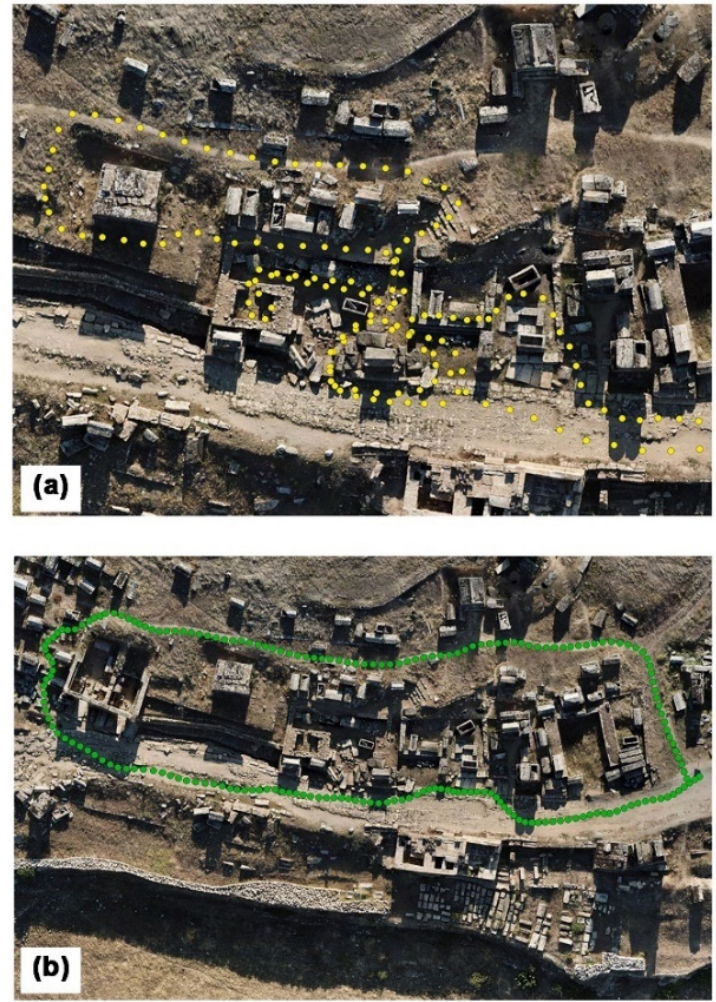

Figure 4: The $159 \mathrm{~b}$ tomb area. Acquisition schemes with the GoPro Fusion: a) Time lapse strategy; b) Video strategy.

For the video approach, the maximum video resolution was adopted $(5.2 \mathrm{~K}, 30 \mathrm{fps})$. The path completed through the area, Figure $4 \mathrm{~b}$, is similar to the one achieved in the time-lapse approach, slightly more peripheral. Also in this case the mean acquisition distance between camera and structures was between 3 and 5 meters. The acquisition was completed in three and a half minutes and an area of $\approx 9.000 \mathrm{~m}^{2}$ was covered.

\section{Data processing and validation}

In the following section, a brief overview of the processing of the data collected in the field campaigns will be reported. More specifically, the 2017 and 2018 UAVs dataset were processed following the standard SfM pipeline (image matching, tie point extraction, bundle block adjustment) and subsequent products generation (densification, DSM, and orthophoto) in the well-known commercial solution Agisoft Metashape. Spherical images were processed with a similar approach, but following specific criteria for a spherical photogrammetric approach (Fangi \& Nardinocchi, 2013; Fangi, Pierdicca, Sturari, \& Malinverni, 2018; Teppati Losè, Chiabrando, \& Spanò, 2018).

Finally, a co-registration approach was tested between the $2018 \mathrm{UAVs}$ and $360^{\circ}$ dataset to enhance the overall photogrammetric processing and reduce the time needed to complete it.

\subsection{UAV data processing}

The data collected in 2017 from the five UAVs flights were processed together in a single photogrammetric project.
In Table 4 the RMS (Root Mean Square) error on both GCPs (Ground Control Points) and CPs (Check Points) is reported, together with the main processing parameters.

Table 4: Northern Necropolis of Hierapolis. 2017 flights processing main characteristics.

\begin{tabular}{c|c|c|c|c}
$\begin{array}{c}N^{\circ} \\
\text { Images }\end{array}$ & $\begin{array}{c}\text { Reprojection } \\
\text { error (mean) }\end{array}$ & $\begin{array}{c}\text { GSD } \\
(\mathrm{cm} / \text { pix })\end{array}$ & $\begin{array}{c}\text { RMSe } \\
\text { GCPs } \\
(\mathrm{m})\end{array}$ & $\begin{array}{c}\text { RMSe } \\
\mathrm{CPS}(\mathrm{m})\end{array}$ \\
\hline 742 & 0.25 pix & 2.9 & 0.036 & 0.036
\end{tabular}

It should be noted that the processing results confirmed the possibility of deploying a COTS platform and covering a wide area of the site. The result achieved can guarantee a representational scale of 1:200. The 2018 manual flights were processed with the same approach and the main processing parameters are reported in Table 5.

Table 5: The 159b tomb area. 2018 flights processing main characteristics.

\begin{tabular}{c|c|c|c|c}
$N^{\circ}$ & $\begin{array}{c}\text { Reprojection } \\
\text { error (mean) }\end{array}$ & $\begin{array}{c}G S D \\
(\mathrm{~cm} / \text { pix })\end{array}$ & $\begin{array}{c}\text { RMSe } \\
\text { GCPs } \\
(\mathrm{m})\end{array}$ & $\begin{array}{c}\text { RMSe } \\
\mathrm{CPS}(\mathrm{m})\end{array}$ \\
\hline 829 & 1.08 pix & 0.07 & 0.007 & 0.008
\end{tabular}

In this case, thanks to the lower altitude of the flights, the higher overlap and the flight scheme adopted it was possible to guarantee the generation of metric products at a nominal scale of 1:50 or even greater.

\subsection{Spherical Photogrammetry}

The first dataset processed and validated is the one acquired with the time-lapse strategy.

After a preliminary stitching phase, that was completed in the software GoPro Fusion Studio, it was decided to downsample the dataset due to a redundant number of images available. A total number of 158 images was thus imported and processed in Metashape, the metric accuracy of the processing was evaluated thanks to 12 control points (6 used as GCPs and 6 as CPs); the main parameters of the processing are reported in Table 6.

Table 6: The $159 \mathrm{~b}$ tomb area. $360^{\circ}$ camera time-lapse approach processing main characteristics.

\begin{tabular}{c|c|c|c|c}
$N^{\circ}$ & $\begin{array}{c}\text { Reprojection } \\
\text { error (mean) }\end{array}$ & $\begin{array}{c}\text { GSD } \\
(\mathrm{cm} / \text { pix })\end{array}$ & $\begin{array}{c}\text { RMSe } \\
\text { GCPs } \\
(\mathrm{m})\end{array}$ & $\begin{array}{c}\text { RMSe } \\
\text { CPS }(\mathrm{m})\end{array}$ \\
\hline 158 & 0.82 pix & 0.47 & 0.021 & 0.024
\end{tabular}

The data contained in the table confirm the overall good performances of this approach: the RMSE on both GCPs and CPs can guarantee a representational scale of 1:100.

The dataset acquired with the video approach was in a first step stitched in the dedicated GoPro software and a spherical video of $\approx 15 \mathrm{~Gb}$ was obtained. Single frames were then extracted from the video (one frame each 30 1 frame per second) obtaining a total number of 202 frames. The main processing parameters of this dataset are reported in Table 7. 
Table 7: The $159 \mathrm{~b}$ tomb area. $360^{\circ}$ camera video approach processing main characteristics

\begin{tabular}{c|c|c|c|c}
$N^{\circ}$ & $\begin{array}{c}\text { Reprojection } \\
\text { error (mean) }\end{array}$ & $\begin{array}{c}G S D \\
(\mathrm{~cm} / \mathrm{pix})\end{array}$ & $\begin{array}{c}\text { RMSe } \\
\mathrm{GCPS} \\
(\mathrm{m})\end{array}$ & $\begin{array}{c}\text { RMSe } \\
\mathrm{CPS}(\mathrm{m})\end{array}$ \\
\hline 202 & 0.11 pix & 0.56 & 0.011 & 0.037
\end{tabular}

To further examine and validate the proposed approaches a TLS dataset was used as ground reference elements as usual in this kind of experimental text (Spanò, Chiabrando, Sammartano, Teppati Losè, 2018). The same area was selected and segmented in the three point clouds and further analyses were performed in CloudCompare software, exploiting the Cloud2Cloud distance tool. The results of these analyses are reported in Table 8.

Table 8: $\mathrm{C} 2 \mathrm{C}$ distance analysis on the $\mathrm{TLS} / 360^{\circ}$ datasets (maximum research distance set to $0,1 \mathrm{~m}$ ).

\begin{tabular}{c|c|c|c|c} 
Model & $\begin{array}{c}<0,03 \\
m\end{array}$ & $\begin{array}{c}<0,02 \\
m\end{array}$ & $\begin{array}{c}<0,01 \\
m\end{array}$ & $\begin{array}{c}<0,005 \\
m\end{array}$ \\
\hline TLS/TimeLapse & $78 \%$ & $65 \%$ & $40 \%$ & $22 \%$ \\
TLS/Video & $69 \%$ & $54 \%$ & $31 \%$ & $16 \%$
\end{tabular}

Considering the overall resolution and number of the images processed in the SfM approach, the overall deviations of the spherical datasets from the TLS one can be considered satisfying. However, it is important to underline the main issues of $360^{\circ}$ generated point clouds. Firstly, the low density of the point cloud if compared with other techniques and secondly the presence of a relatively diffused noise. These issues relate to the resolution of the 360 images used and the high distortion present in the stitched 360 images that influence the overall process. Finally, it should be noted that the video dataset is performing a little worse than the time lapse one. This issue is connected with the geometry of the acquisition and also with the little reduction of image quality due to the choice of recording video and not images.

\subsection{Co-registration approach}

To reduce the time needed for the processing of the $360^{\circ}$ dataset and especially the solution of the E.O. (Exterior Orientation) phase, a co-registration approach was tested and validated using the already processed UAVs dataset of 2018 and the $360^{\circ}$ dataset acquired in time lapse mode.

The UAVs dataset, acquired a few hours before the $360^{\circ}$, was processed in first instance in the standard photogrammetric pipeline; as already described and reported in Table 5 . The spherical images were thus imported into the UAVs processed dataset to use the aerial images as a rigid block to orient the terrestrial acquisition. To validate the overall accuracy of this approach two quality checks were performed:

- Coordinates of camera stations derived from the co-registration approach were compared with the ones derived from the standard processing (Table 6);

- Similar analyses were completed using a set of control points.
A view of the camera stations of the two datasets is reported in Figure 5.

The first analysis was performed after extracting the coordinates estimated for all the camera stations both from the traditional processing performed for the timelapse dataset, both for the processing performed with the co-registration approach. For this analysis deviations between the two sets were evaluated for $\mathrm{x}, \mathrm{y}$, and $\mathrm{z}$ components separately. The values derived from this analysis are reported in Table 9 with also the mean value of these deviations and the standard deviation for all the reported parameters analysed.
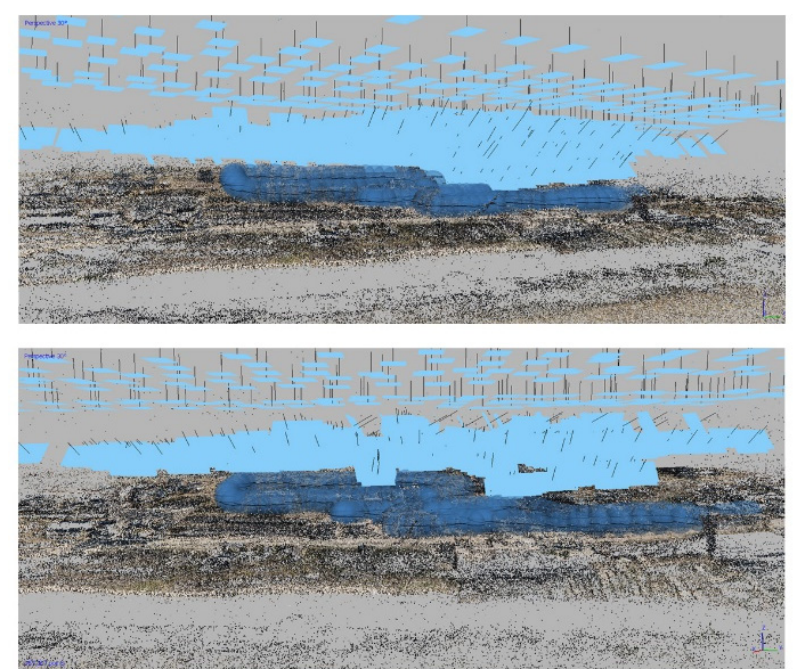

Figure 5: Hierapolis, the $159 \mathrm{~b}$ tomb area. Co-registration of $360^{\circ}$ dataset (dark blue) with the UAVs acquisition (light blue).

The data reported in the table shows that the estimation of camera stations coordinates adopting the coregistration approach is delivering good results in terms of accuracy. The mean value of the deviation is lower than $0,03 \mathrm{~m}$ for all the three components and there are no particular trends to underline, except for the standard deviation value of the $x$ component that presents a higher value and needs to be further investigated. This issue can be related with the direction of the flight lines, that is perpendicular in relation to the $x$ axis of the reference system, however further tests and analyses are needed to clarify this aspect. The data derived from this analysis were also represented in a gaussian distribution (Fig. 6).

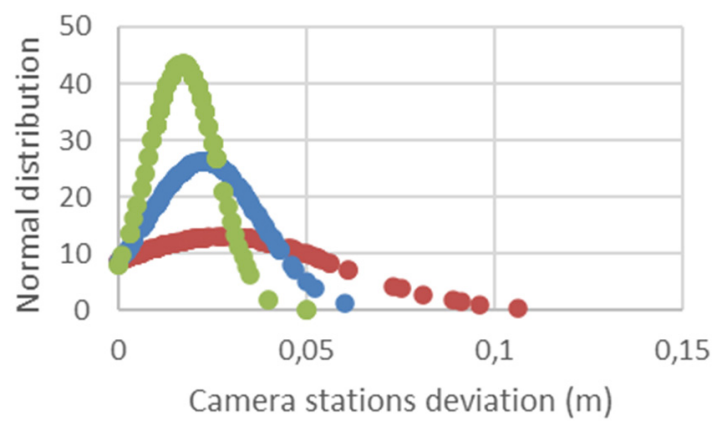

$\bullet X \bullet P Z$

Figure 6: Graphical representation of the normal distribution of the deviation in the three coordinates components between the camera positions estimated with the co-registration and the traditional approach. 
On the other hand, the second analysis was performed using as reference a set of control points measured in the field with a total station; after the co-registration approach, the coordinates of this set of points were estimated in the photogrammetric software (they were computed as manual Tie Points). The results of this analysis are reported in Table 10.

The second analysis, reported in the previous table, allowed to confirm the overall good accuracy of this approach, however, by mean of this analysis, it was possible to highlight an error on the deviation for the $z$ coordinate. This issue is probably derived from a wrong estimation of I.O. (Interior Orientation) parameters and a weak acquisition geometry. However, this is an issue that needs to be further investigated to identify which elements are causing it.

After the solution of the E.O. adopting the co-registration approach, the photogrammetric processing can be completed excluding the UAVs images.

Table 9: Co-registration approach, comparison on the coordinates of camera stations estimated with the co-registration approach and with the traditional approach.

\begin{tabular}{c|c|c|c|c|c|c|c|c}
$\begin{array}{c}N^{\circ} \\
\text { cameras }\end{array}$ & $\begin{array}{c}\Delta X \\
(m)\end{array}$ & $\begin{array}{c}\Delta Y \\
(m)\end{array}$ & $\begin{array}{c}\Delta Z \\
(m)\end{array}$ & $\begin{array}{c}\text { Mean } \Delta \\
(m)\end{array}$ & $\begin{array}{c}\text { Std. Dev. } \Delta X \\
(m)\end{array}$ & $\begin{array}{c}\text { Std. Dev. } \Delta Y \\
(m)\end{array}$ & $\begin{array}{c}\text { Std. Dev. } \Delta Z \\
(m)\end{array}$ & $\begin{array}{c}\text { Mean Std. Dev. } \Delta \\
(m)\end{array}$ \\
\hline 158 & 0.028 & 0.023 & 0.017 & 0.022 & 0.031 & 0.015 & 0.009 & 0.018
\end{tabular}

Table 10: Co-registration approach, comparison on the coordinates of control points derived from co-registration approach and topographic measured.

\begin{tabular}{c|c|c|c|c|c|c|c|c}
$\begin{array}{c}N^{\circ} \text { control } \\
\text { points }\end{array}$ & $\begin{array}{c}\Delta X \\
(m)\end{array}$ & $\begin{array}{c}\Delta Y \\
(m)\end{array}$ & $\begin{array}{c}\Delta Z \\
(m)\end{array}$ & $\begin{array}{c}\text { Mean } \Delta \\
(m)\end{array}$ & $\begin{array}{c}\text { Std. Dev. } \Delta X \\
(m)\end{array}$ & $\begin{array}{c}\text { Std. Dev. } \Delta Y \\
(m)\end{array}$ & $\begin{array}{c}\text { Std. Dev. } \Delta Z \\
(m)\end{array}$ & $\begin{array}{c}\text { Mean Std. Dev. } \Delta \\
(m)\end{array}$ \\
\hline 8 & 0.018 & 0.027 & 0.064 & 0.036 & 0.011 & 0.028 & 0.019 & 0.019
\end{tabular}

\subsection{Consideration in the generation of metric products suitable for the archaeological research}

Before moving to the phase of metric products generation in agreement with the archaeological needs for the studying of this area it was decided to perform some further analyses and comparisons between the different datasets available.

The first dataset investigated in this sense was the one derived from the different UAVs acquisitions. A first qualitative analysis was achieved on the DSMs generated from different scale surveys $(2017,2018)$, which is shown in Figure 7.

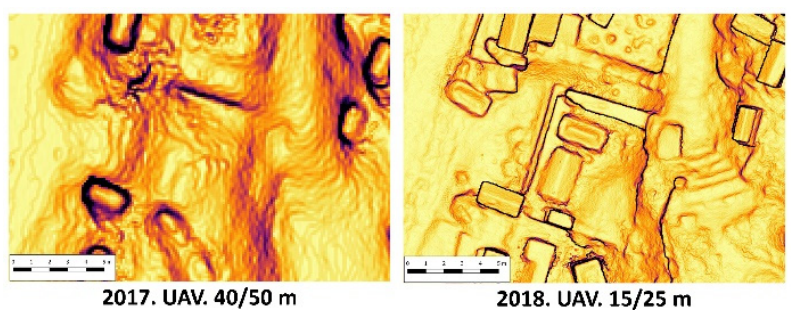

Figure 7: Hierapolis, the $159 \mathrm{~b}$ tomb area. DSMs generated from 2017 and 2018 UAVs datasets, generated from flights performed at different altitudes.

Another qualitative analysis was then achieved on the same datasets but on a different product: the orthophoto. An extract of the orthophotos generated from the two datasets is shown in Figure 8.

As is possible to notice from both the analyses on the DSM and orthophoto it is clear, as expected, that reducing the flight altitude is a crucial element to reach a higher level of detail. The 2017 dataset, which was perfect for general documentation of the area and its main features, was not sufficient to support the archaeological research in this area, a role that can be fulfilled with the 2018 dataset.

Another analysis was completed thanks to the qProf plugin developed for Qgis, which allows extracting height and slope profiles from the DSM, as shown in Figure 9; in this case, the analysis was replicated both in 2017 and 2018 datasets, to evaluate the different characteristics of the two datasets.

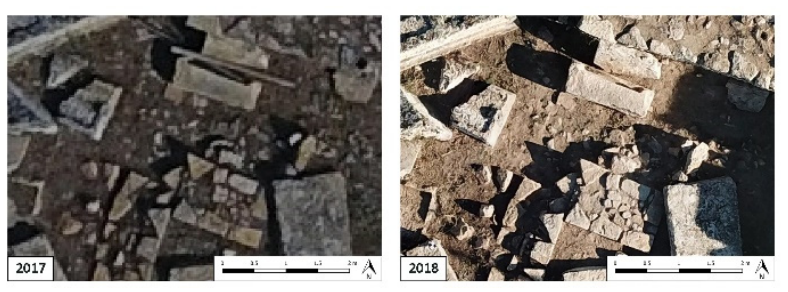

Figure 8: Hierapolis, the $159 \mathrm{~b}$ tomb area. Qualitative analysis between 2017 and 2018 orthophotos generated from flights performed at different altitudes.

It should be reported that the different resolutions of the two datasets are clearly impacting also the resolution of the details that can be extracted from the DSM.

As already underlined from the RMSE of the control points and as confirmed from the analyses presented in this section the 2017 dataset is able to guarantee a 1:200 scale, that suits the need for a general description of the area of interest at a territorial scale, while the 2018 dataset reach a 1:50 scale, that is perfect for the subsequent archaeological studies.

Similar analyses were also performed for the $360^{\circ}$ dataset. An extract of the DSM is reported in Figure 10.

It is interesting to compare this DSM with the UAVs one. The model generated from the $360^{\circ}$ dataset can be considered as completed as the UAV one in terms of the level of detail. As already reported, the 360 model is however characterized by a diffuse noise and this issue is 
clearly visible also on the DSM. However, despite this noise, the terrestrial DSM is as complete as the one generated from the UAVs dataset and also at a bigger scale.
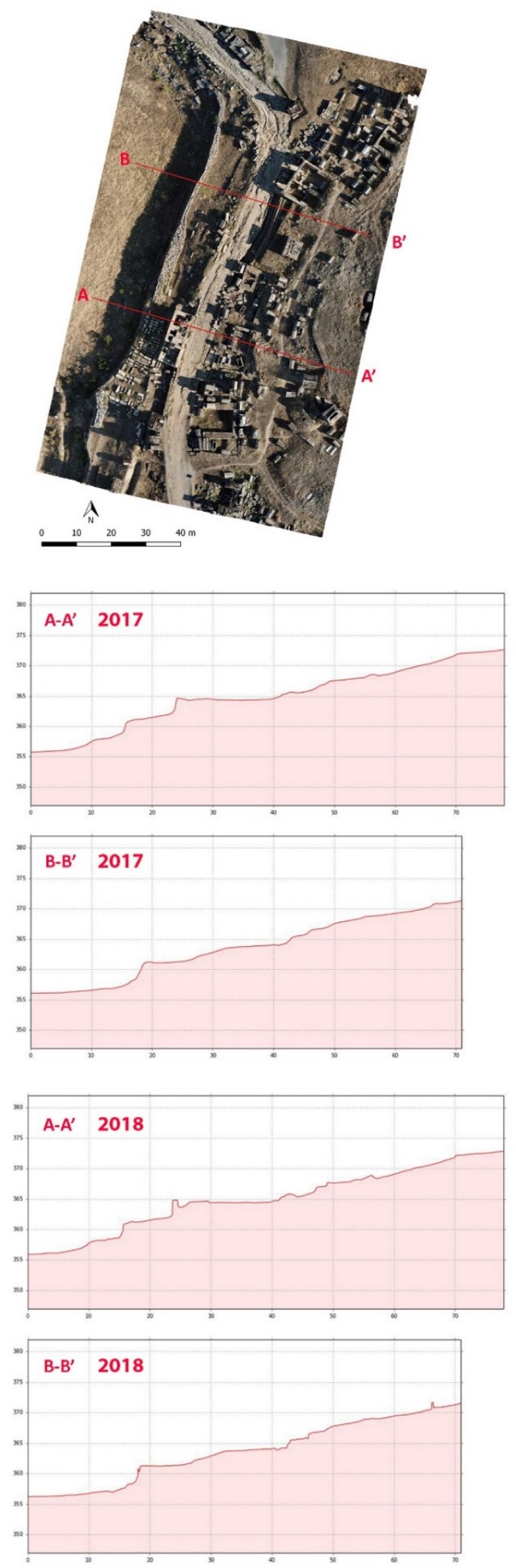

Figure 9: Terrain profiles generated with the qProf plugin, 2017 (top) and 2018 (down).

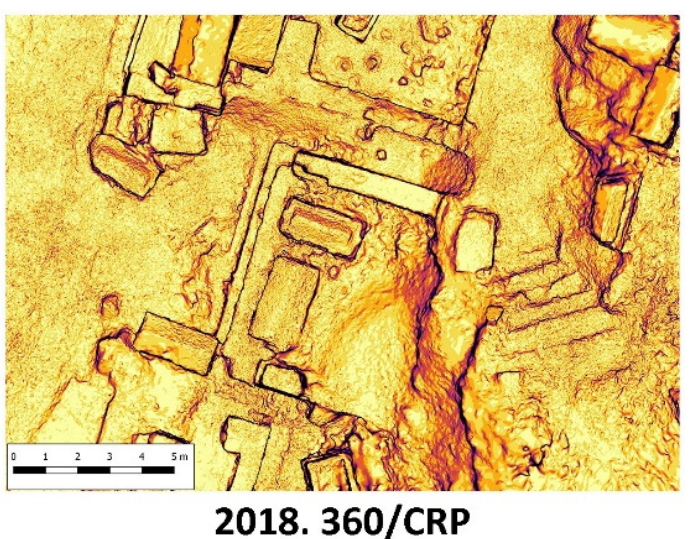

Figure 10: Hierapolis, the $159 \mathrm{~b}$ tomb area. Extract of the DSM generated from the 2018 spherical dataset.

Finally, the qProf plugin was used also to extract profiles from the $360^{\circ}$ model. Two examples of these profiles are shown in Figure 11. In this case the resolution of the dataset allowed to extract profiles also in a smaller area. Profile A-A' can be used to define the connection between the archaeological remains and the road that crosses the area, while profile B-B' can define the stone steps of a smaller route that connected different levels of the area.

\section{Use of the derived products in the archaeological research}

Archaeological investigations conducted by the University of Pisa between 2017 and 2019 resulted in a clearer understanding of the system of terraces and of the internal articulation in the area between Tombs $163 d$ and 159d (Anguissola, forthcoming; Anguissola, \& Costa, 2020). Thanks to the information provided by the 2018 campaign of images and data acquisition (see above), a number of crucial points with significant gradient have been detected and have received closer consideration (e.g., surface cleaning and close-up drawing of individual architectural features) (Fig. 12).

In particular, attention focused on Tomb 159c, a monumental grave that seems to have undergone several changes in layout and ownership.

Tomb 159c, surrounded by a funerary enclosure (for which several parallels exists in both the South-Western necropolis, e.g. Tomb S10, and the Nothern necropolis, e.g. Tombs A18, 2, 142, 156, 156a e 163b-g), occupies a large area along the main street leading towards Tripolis and the Meander Valley. Examination of the collapsed architectural elements belonging to the monument has allowed identifying a large inscribed limestone lintel bearing the name of $\Phi \lambda$. ФІ入ímmou ( $F l$. Philippou), probably the person who owned the tomb (or a part thereof) at some point in the $4^{\text {th }}$ century CE.

An imposing funerary chamber, originally covered by a barrel vault (see parallels in Tombs A20, A22, 45, 150a and $150 \mathrm{~b}$ in the Northern Necropolis, Tombs D16 and D33 in the South-Eastern necropolis, and Tomb E182 in the Eastern necropolis), stands at the north end of the area included in the enclosure. Two sarcophagi to the east of the enclosure bear lengthy Greek inscriptions, dating to the $3 \mathrm{rd}$ and the $4^{\text {th }}$ centuries CE respectively. They explain that an area of $15 \times 6$ cubiti, as well as some of the sarcophagi placed in the tomb and the heroon (i.e., 
an 'heroic', monumental grave) "to the left of those who enter the enclosure" belonged first to a man named Marcus Aurelius Rouphos Asklepianos, and later to the deacon Theodoros.
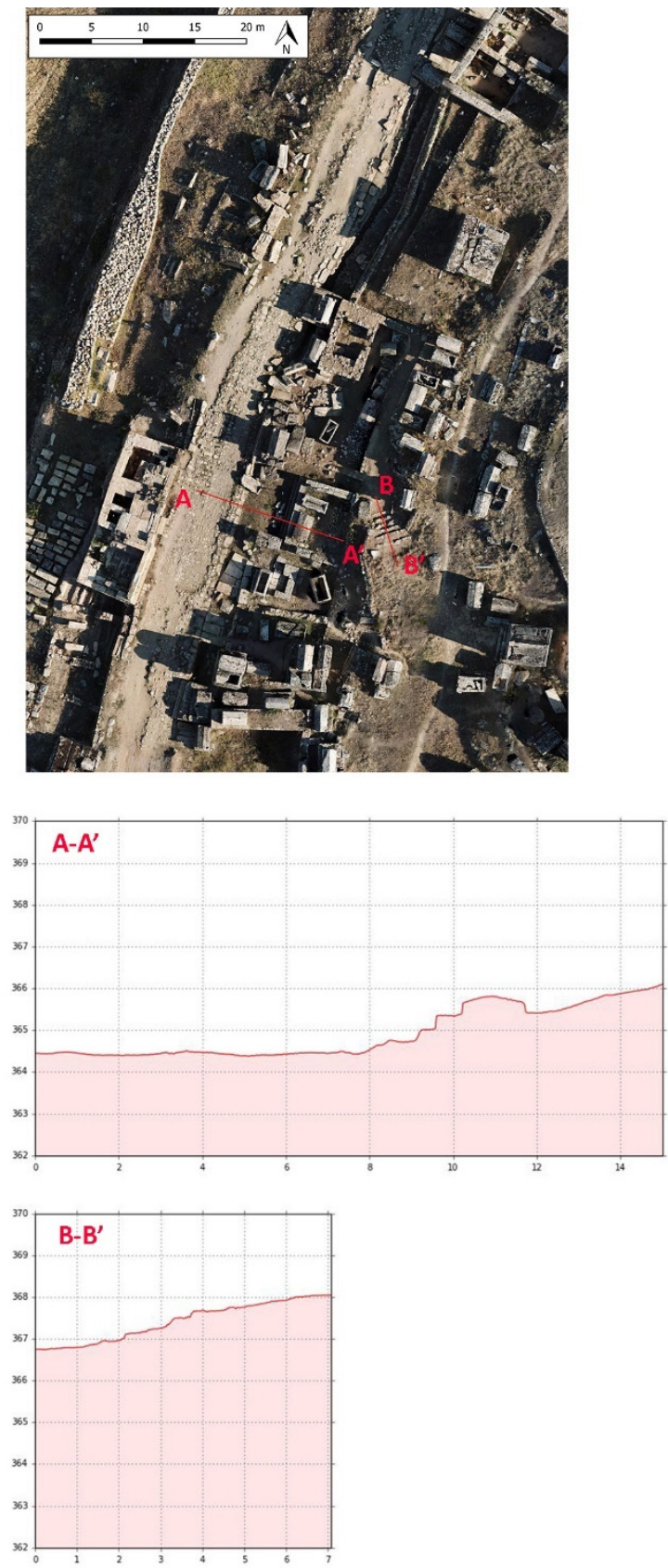

Figure 11: Terrain profiles generated with the qProf plugin from the 360 model.

The inscriptions' singular insistence on both the size of the area, smaller than the entire Tomb 159c, and the position of the heroon - which is likely identified with the monumental funerary chamber, "to the left of those who enter" - seemed to require further investigation. The orthophotos generated from the 2017 UAVs dataset (above, Figure 8) suggested a way to address this apparently enigmatic abundance in details. The orthophotos revealed the previously undetected remains of a second, smaller chamber that once stood in the southern part of the enclosure - that is, a much less stately building placed to the right for those entering the funerary area. The presence of a second, smaller chamber, which may have belonged to a different individual or family, would explain the need for both Marcus Aurelius Rouphos Asklepianos and Theodoros to describe explicitly the size and location of their grave. Perhaps, most of the open-air area and the smaller chamber belonged in the $4^{\text {th }}$ century CE to FI. Philippos, whose name was inscribed above the entrance.

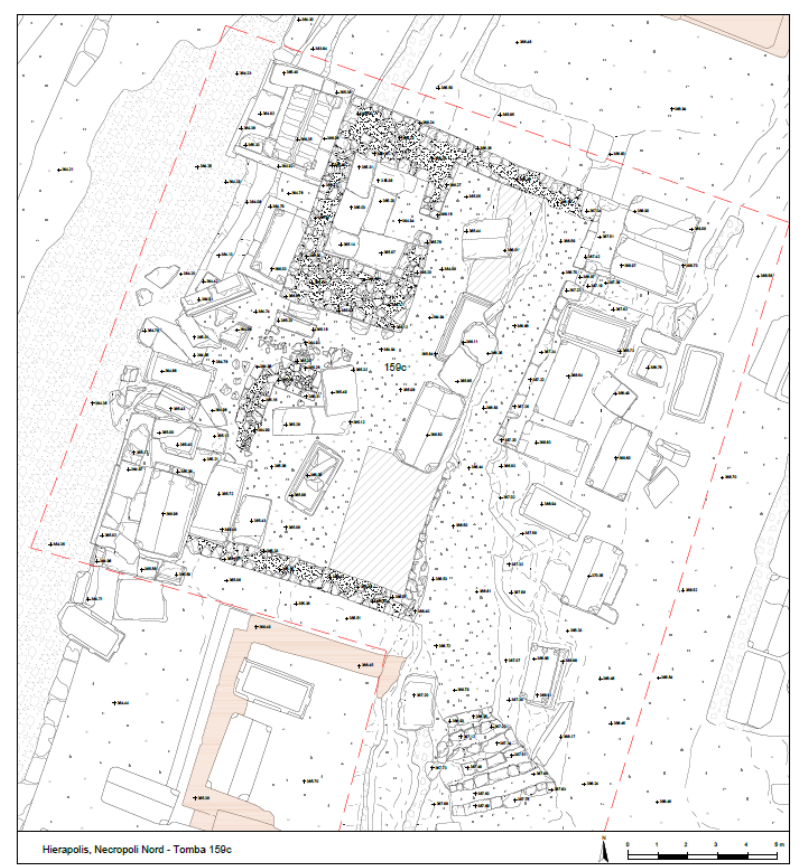

Figure 12: Hierapolis, Northern Necropolis. Tomb 159c and immediate surroundings, with indication of altitudes.

It is impossible to determine whether Tomb 159c was first built during the $3^{\text {rd }}$ century $C E$, when the earliest of the two inscribed sarcophagi must have been placed inside the enclosure. However, as is clear in the terrain profiles extracted in Qgis with the qProf plugin on the 360 acquisition (above, Figure 11), this large complex altered significantly the existing layout of the necropolis. Tomb $159 \mathrm{c}$ blocked direct circulation from the main street to the upper terrace of the necropolis, by destroying what must have been a rather large road leading upwards to a large staircase (above, Figure 11, profile B-B', and Figure 13, Left).
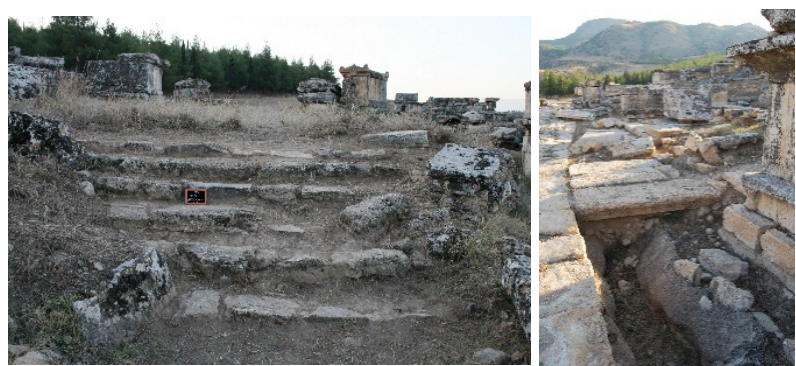

Figure 13: Hierapolis, Northern Necropolis. (Left) Stairs leading to the upper terrace from the South-West corner of Tomb 159c, 2018 (Right) Channel running along the main street.

A further, equally relevant moment in the life of Tomb $159 \mathrm{c}$ - and of the whole necropolis - is the progressive occupation of the public soil in front of the funerary buildings in the first row, thus concealing the channel 
along the main street (Figure 13, Right). The burial ground seems to have grown at an impressively fast pace, to the point that it became virtually impossible to enforce orderly

\section{Conclusions and further perspectives}

The research presented in this work was aimed at testing different approaches, both consolidated and more experimental, to flank the archaeological research in the area of the Northern Necropolis of Hierapolis. The potential of UAVs as a means for completing rapid mapping approaches were confirmed once again. Issues related to flight plan and acquisition distance have been investigated both during the field acquisition, the processing phase and the generation of the required products.

On the other hand, the first tests on the use of $360^{\circ}$ cameras delivered encouraging results as well as different issues that need to be further investigated in future research. Starting from the different modalities of acquisition that can be deployed in the field to an analysis of the different products generated from this kind of sensor several topics have been explored.

Moreover, the tests aimed to validate the possibility of integrating multi-sensor acquisitions, one terrestrial and one aerial, to enhance operations both in the field and in the processing. A co-registration approach would allow the operator to perform in the field the positioning and measuring of a single set of control points or to use datasets collected in different periods. Moreover, the two sensors were deployed adopting different acquisition distances and it is thus possible to perform also a multiscale approach. The tests performed on the coregistration approach underlined some issues in the estimation of the camera position of the co-registered dataset, an aspect that requires further tests to be better understood and validated.

Finally, the potential of an integrated approach, based on geomatics techniques - and in particular COTS methods - could be fully exploited by extending consideration to the whole Northern Necropolis of Hierapolis. A large-scale investigation could provide invaluable data to address issues of circulation, ownership, organization, and urban planning. One possible avenue of investigation includes surveying the features that attest to both existing and disrupted pathways (such as stairs, steps, and stone benches). These elements, seen in the light of the large body of funerary inscriptions available at Hierapolis, allow reconstructing the ancient landscape throughout a long period of time. In this perspective, a clearly defined set of 'connective' features could account for changes in layout which, in turn, mirror major transformations in the social and economic fabric of the town, as well as in the funerary practices of the Roman world (Anguissola, Costa, \& Monticolo, forthcoming).

In particular, mapping the roughly 170 stone benches and seats (according to a catalogue made in 2019) attached to monumental tombs or funerary precints from various periods (among which two semi-circular exedrae, Tombs 55 and 147a), may provide insightful clues about passageways, boundaries, the layout of terraces, and points of increased visibility throughout the entire life of the necropolis (Fig. 14).

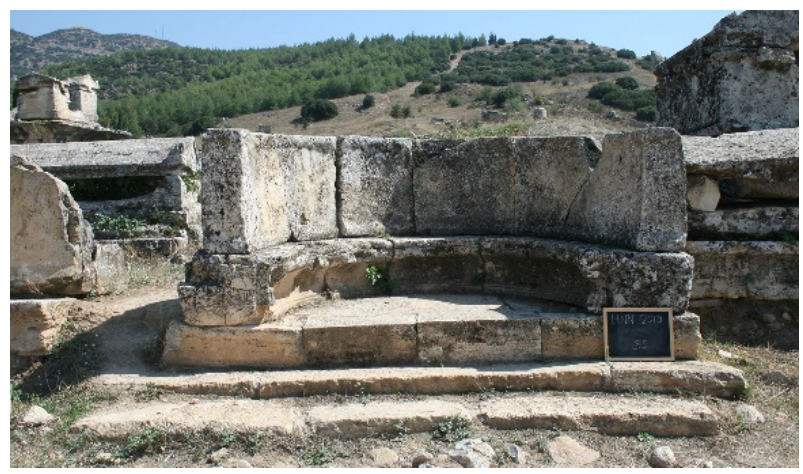

Figure 14: Hierapolis, Northern Necropolis. Tomb 55 (exedrashaped bench), 2019.

\section{Acknowledgements}

The present study was carried out within the PRIN project titled Archeologia dei paesaggi urbani in Asia Minore tra tardo ellenismo ed età bizantina. Approcci multidisciplinari allo studio di Hierapolis di Frigia., principal investigator G. Semeraro, resp for Geomatics unit A. Spanò, Resp. for acheologists equipe studying Hierapolis necropolis, A. Anguissola.

The authors would like to thank Giulia Sammartano, Silvana Costa and Antonio Monticolo, for geomatics data acquisition and archaeological studies respectively.

\section{References}

Anguissola, A. (forthcoming). Nuovi dati per la conoscenza dei paesaggi funerari di Hierapolis di Frigia. La Tomba 159c della Necropoli Nord. АГ $\Omega Г \mathrm{H}, 14-16$

Anguissola, A., Bochicchio, L., Calabrò, A., \& Costa, S. (2012). Challenging Local Traditions: The South-Western Necropolis at Hierapolis in Phrygia. 7ICAANE. Proceedings of the 7th International Congress on the Archaeology of the Ancient Near East (Harrassowitz Verlag, Ed.). Wiesbaden, 3, 417-435.

Anguissola, A., Bochicchio, L., Calabrò, A., \& Costa, S. (2013). Funerary architecture at Hierapolis in Phrygia: the southwestern necropolis. SOMA 2012. Identity and Connectivity (BAR International, Ed.). Oxford, 457-465.

Anguissola, A., Bochicchio, L., Calabrò, A., \& Costa, S. (2014). Research in the South-Western Necropolis at Hierapolis in Phrygia: the Tomb of the Dragons (S2). 8 ICAANE. Proceedings of the 8th International Congress on the Archaeology of the Ancient Near East (Harrassowitz Verlag, Ed.). Wiesbaden, 2, 619-629.

Anguissola, A., Bochicchio, L., Calabrò, A., \& Costa, S. (2016). La necropoli Sud-Ovest a Hierapolis di Frigia: lo scavo della tomba di Tiberius Claudius Thalamos (S10). Hierapolis di Frigia VIII. Le attività delle campagne di scavo e restauro, 2007-2011 (E. Yayinlari, Ed.). Istanbul, 2, 503-527.

Anguissola, A., \& Costa, S. (2020). I sarcofagi della Necropoli Nord di Hierapolis in contesto: due casi di studio, Studi 
Classici e Orientali, 66, 301-328

Anguissola, A., Costa, S., \& Monticolo, A. (forthcoming). Ricerche nella necropoli nord a Hierapolis di Frigia. Le campagne 2017-2019 nell'area delle Tombe 156-163. ArcheoLogica Data.

Chiabrando, F., D’Andria, F., Sammartano, G., \& Spanò, A. (2018). UAV photogrammetry for archaeological site survey. $3 \mathrm{~d}$ models at the hierapolis in Phrygia (Turkey). Virtual Archaeology Review, 9(18), $28-43$. https://doi.org/10.4995/var.2018.5958

Chiabrando, F., Lingua, A., Maschio, P., \& Teppati Losè, L. (2017). The influence of flight planning and camera orientation in UAVs photogrammetry. A test in the area of rocca San Silvestro (LI), Tuscany. In International Archives of the Photogrammetry, Remote Sensing and Spatial Information Sciences - ISPRS Archives, 42. https://doi.org/10.5194/isprs-archives-XLII-2-W3-163-2017

Chiabrando, F., \& Teppati Losè, L. (2017). Performance evaluation of COTS UAV for architectural heritage documentation. A test on s.giuliano Chapel in Savigliano (CN) - Italy. In International Archives of the Photogrammetry, Remote Sensing and Spatial Information Sciences - ISPRS Archives, 42, 77-84. https://doi.org/10.5194/isprs-archives-XLII2-W6-77-2017

D’Andria, F., Scardozzi, G., \& Spanò, A. (2008). Atlante di Hierapolis di Frigia. (E. Yayinlari, Ed.). Istanbul.

D'Annibale, E., Piermattei, L., \& Fangi, G. (2011). Spherical Photogrammetry As Emergency Photogrammetry. XXIII CIPA Symposium.

Fangi, G., \& Nardinocchi, C. (2013). Photogrammetric processing of spherical panoramas. Photogrammetric Record, 28(143), 293-311. https://doi.org/10.1111/phor.12031

Fangi, G., Pierdicca, R., Sturari, M., \& Malinverni, E. S. (2018). Improving spherical photogrammetry using $360^{\circ} \mathrm{OMNI-}$ Cameras: Use cases and new applications. In International Archives of the Photogrammetry, Remote Sensing and Spatial Information Sciences - ISPRS Archives, 42, 331-337). https://doi.org/10.5194/isprs-archives-XLII-2-3312018

Gottardi, C., \& Guerra, F. (2018). Spherical images for cultural heritage: Survey and documentation with the NIKON KM360. In International Archives of the Photogrammetry, Remote Sensing and Spatial Information Sciences - ISPRS Archives, 42, 385-390. https://doi.org/10.5194/isprs-archives-XLII-2-385-2018

Hernández-Lopez, D., Felipe-Garcia, B., Gonzalez-Aguilera, D., \& Arias-Perez, B. (2013). An automatic approach to UAV flight planning and control for photogrammetric applications: A test case in the asturias region (Spain). Photogrammetric Engineering and Remote Sensing, 79(1), 87-98. https://doi.org/10.14358/PERS.79.1.87

Nex, F., \& Remondino, F. (2014). UAV for 3D mapping applications: A review. Applied Geomatics, 6(1), 1-15. https://doi.org/10.1007/s12518-013-0120-x

Ramos, A. P., \& Prieto, G. R. (2016). Only image based for the 3D metric survey of gothic structures by using frame cameras and panoramic cameras. International Archives of the Photogrammetry, Remote Sensing and Spatial Information Sciences - ISPRS Archives, 41(July), 363-370. https://doi.org/10.5194/isprsarchives-XLI-B5-363-2016

Remondino, F., Barazzetti, L., Nex, F., Scaioni, M., \& Sarazzi, D. (2012). Uav Photogrammetry for Mapping and 3D Modeling - Current Status and Future Perspectives. ISPRS - International Archives of the Photogrammetry, Remote Sensing and Spatial Information Sciences, XXXVIII-1/(September), 25-31. https://doi.org/10.5194/isprsarchivesXXXVIII-1-C22-25-2011

Scardozzi, G. (2015). Nuovo Atlante di Hierapolis di Frigia. Cartografia archeologica della città e delle necropoli (E. Yayinlari, Ed.). Istanbul.

Spanò, A., Chiabrando, F., Sammartano, G., Teppati Losè, L. (2018). Integrated imaging approaches supporting the excavation activities. multi-scale geospatial documentation in Hierapolis (TK)", in International Archives of the Photogrammetry, Remote Sensing and Spatial Information Sciences, XLII-2.

Teppati Lose', L. (2019). Geomatics support to the metric documentation of the archaeological heritage. Tests and validations on the use of low-cost, rapid, image-based sensors and systems. Italy. Retrieved from https://iris.polito.it/handle/11583/2735515\#.X0_6n8gzZEY

Teppati Losè, L., Chiabrando, F., \& Spanò, A. (2018). Preliminary evaluation of a commercial 360 multi-camera RIG for photogrammetric purposes. In International Archives of the Photogrammetry, Remote Sensing and Spatial Information Sciences - ISPRS Archives 42, 1113-1120. https://doi.org/10.5194/isprs-archives-XLII-2-1113-2018 